\title{
A Study to Assess the Psychosocial Problems and Quality of Life of Parents with Asthmatic Children in Opd's of Ramaiah Hospitals, Bengaluru
}

\author{
Somashekar Ankanahalli Ramu*, Arpitha Panduranga, S. Akarsh \\ Department of Pediatrics, Ramaiah Medical College and Hospital, Bangalore, India \\ Email: *s_arshekar2002@yahoo.com
}

How to cite this paper: Ramu, S.A., Panduranga, A. and Akarsh, S. (2018) A Study to Assess the Psychosocial Problems and Quality of Life of Parents with Asthmatic Children in Opd's of Ramaiah Hospitals, Bengaluru. Open Journal of Pediatrics, 8, 50-57.

https://doi.org/10.4236/ojped.2018.81007

Received: August 21, 2017

Accepted: March 5, 2018

Published: March 8, 2018

Copyright $\odot 2018$ by authors and Scientific Research Publishing Inc. This work is licensed under the Creative Commons Attribution International License (CC BY 4.0).

http://creativecommons.org/licenses/by/4.0/

\begin{abstract}
The study was undertaken to assess the level of psychosocial problems and quality of life of parents with asthmatic children in Ramaiah hospitals, Bengaluru. Statement of the problem: "A study to assess the psychosocial problems and quality of life of parents with asthmatic children in opd's of Ramaiah hospitals, Bengaluru". Objectives of the study: 1) To assess the level of psychosocial problems and level of quality of life of parents with asthmatic children. 2) To find the correlation between scores of psychosocial problem and quality of life among parents with asthmatic children. 3) To find the association between level of psychosocial problem and selected socio demographic variables. 4) To find the association between level of quality of life and selected socio-demographic variable. Method: A descriptive survey approach was used for the study. Purposive sampling technique was used to select 50 parents with asthmatic children. Data was collected through interview schedule by using structured rating scale to assess psychosocial problems and quality of life. Data was collected and analyzed using descriptive and Inferential statistics in terms of frequencies, Percentage, Mean, Mean percentage, Standard deviation, Karl Pearson's correlation co-efficient and chi-square test. Findings: The major findings of the study indicated that majority of the parents with asthmatic children that is 33 (66\%) were having moderate psychosocial problems and $16(32 \%)$ were having mild psychosocial problem and 1 (2\%) were having severe psychosocial problem and 38 (76\%) were having good quality of life, 8 (16\%) were having better quality of life and $4(8 \%)$ were having poor quality of life. Karl Pearson's correlation co-efficient test revealed that there is a correlation that exists between psychosocial problem and quality of life of parents with asthmatic children 0.314 weak positive correlation.
\end{abstract}


Chi-square test revealed that there was no significant association between level of psychosocial problems and quality of life with selected socio demographic variables at 0.05 level of significance. Interpretation and conclusion: The findings show that majority of the parents with asthmatic children had moderate level of psychosocial problems (66\%) and majority had good quality of life $(76 \%)$. There is no significant correlation between psychosocial problem and quality of life. There is no significant association between psychosocial problem and quality of life with selected socio demographic variable. This null hypothesis was accepted.

\section{Keywords}

Psychosocial Problems, Parents with Asthmatic Children, Quality of Life, Socio Demographic Variable

\section{Introduction}

Asthma is reversible obstructive process characterized by an increased responsiveness and inflammation of the lower airways. Bronchial constriction is normal reaction to foreign stimuli, but in asthmatic it is abnormal severe, producing impaired function [1].

A longitudinal study has indicated that the incidence of school age asthma cases has increased eight times during the past 20 years in Taiwan [2]. The percentage of severe asthma cases also increased from $8 \%$ to $20 \%$, according to one recent hospital based study. The recurrent signs and symptoms of asthma are child absenteeism from school, poor academic performance and psychosocial adaptation problems and also one-third of school aged asthma children have some psychosocial problems.

Pediatric asthma is a serious global problem. A conservative estimation worldwide indicates prevalence between $2.8 \%$ to $10.8 \%$ among children. Quality of life refers to a state of wellbeing of parents i.e. the ability to perform every day activities that reflects their physical, psychological, environmental and social wellbeing and parent's satisfaction. An estimated 1.9 disability adjusted life years (DALYs) is lost every year due to asthma per thousand children under 15 years of age in India [3]. Children with very severe asthma tend to have worse quality of life than children with milder disease. It is also shown that not only will quality of life do not correlate with asthma control; it is very distinct component of overall health status [4]. A study done in 26 Latino parents of children of asthma showed that the parents with asthma would make attempts to understand this condition, doing activities with family member, and maintaining an optimistic perspective [5]. A study on mothers of children with asthma consisting of 160 mothers of 4 - 15 years of old children with asthma and the control group consisted of 90 mothers of healthy children. Results indicated that levels of depression and anxiety symptoms were higher in mothers of children with asthma compared to those in the control group $(p<0.0001)$ [6]. 


\section{Methodology}

The research design selected for this study is a non-experimental descriptive research design. In this study purposive sampling technique was used to select the samples based on inclusive and exclusive criteria. Study variables are psychosocial problems and quality of life. The hospital selected for the data collection was Ramaiah hospitals, Bengaluru. The criterion for selecting this setting was feasibility for conducting the study, availability of the sample and familiarity of the investigator with the settings. Duration of study is 6 months (2015). Accordingly 50 parents with asthmatic children who fulfilled the selection criteria were selected as the sample for study. Exclusion criteria were parents with children having other medical disorders.

\subsection{The Tool Used in the Present Study Consisted of}

Section A: Socio demographic variables such as age, gender, educational status, occupation, family income, type of family, religion, place of residence, number of children, duration of child's illness, money to be spent on child's illness.

Section B: Structured questionnaires related to psychosocial problems.

Section C: Questionnaires related to quality of life.

\subsection{Statistical Analysis}

The data obtained was analyzed in terms of the objective of the study using descriptive and inferential statistics

${ }^{*}$ Descriptive statistics

Frequency and percentage distribution was used to describe the socio demographic variables.

Mean, mean percentage and standard deviation was used to describe the level of knowledge on prevention of infection in neonates.

*Inferential statistics

Chi-square test was used to determine the association between level of psychosocial problems and quality of life and selected socio demographic variables.

\section{Results}

The data collected were analyzed according to the plan for data analysis, which includes both descriptive and inferential statistics. The findings have been organized and presented under 3 sections.

\subsection{Section A: Socio Demographic Variables of Parents with Asthmatic Children}

Frequency and percentage distribution with regard to age, gender, religion, education of the parents, family, residence, income, occupation of the parents, number of children, age, gender, duration of illness, No of hospitalization of the child of the parents with asthmatic children $n=50$. 
The majority of respondents 21 (42\%) belong to the age group 32 - 36 years whereas belongs to the age group, 11 (22\%) belongs to the age group of $27-31$ years, 37 - 41 years 22 - 26 years of age and 4 (8\%) belong to the age group of 42 - 46 years. With regard to gender, majority of respondents 35 (70\%) were females whereas 15 (30\%) were males. according to the religion, majority of parents $40(80 \%)$ belonged to Hindu caste. In relation to the education, majority of the parents $40(80 \%)$ are qualified as degree and above, whereas $9(18 \%)$ are qualified as Puc and 1 (12\%) are qualified as higher education.

With regard to type of family majority of 39 (78\%) were nuclear 5 (10\%) were joint and $1(2 \%)$ were extended family. In relation to place of residence 47 (94\%) were urban area and 3 (6\% 0 were rural area. In relation to the monthly income having RS 31,000 - 45,000, 9 (18\%) were having 46,000 - 60,000, 1000 - 15,000. With regard to the occupation $40(80 \%)$ are working as private employers, 7 (14\%) parents are not working, $3(6 \%)$ are government employee.

In relation to the number of children $30(60 \%)$ of parents are having two children, 15 (30\%) of parents are having 1 child and 5 (10) are having 3 children. In relation to the gender of the child $30(60 \%)$ are male child and $20(40 \%)$ are female child. with regard to the age of the child with asthma, majority 27 (54\%) are in the age group of 6 - 10 years, $19(38 \%)$ are in age group 11 - 15 years 4 (8\%) are in the age group of 1 - 5 years. In relation to 27 (54\%) of the child with asthma were in the 1 - 3 years of duration, 19 (38\%) were having 4 - 6 years of duration of illness, 4 (8\%) were 7 and above.

\subsection{Section B}

\subsubsection{Assess the Level of Psychosocial Problem of Parents with Asthmatic Children}

This showed the level of psychosocial problem on parents with asthmatic children, out of among 50 subjects $66 \%$ (33) had moderate psychosocial problem, $2 \%$ (16) had mild psychosocial problem and 1 (2\%) had severe psychosocial problem.

\begin{tabular}{cccc}
\hline Sl no & Category & Frequency & Percentage (\%) \\
\hline 1 & Mild & 16 & 32 \\
2 & Moderate & 33 & 66 \\
3 & severe & 1 & 2 \\
\hline
\end{tabular}

\subsubsection{Mean and Standard Deviation to Assess the Level of Psychosocial Problem with Asthmatic Children $\mathbf{n}=\mathbf{5 0}$}

The table shows the maximum score of psychosocial problems was 41 with mean psychosocial problem 25.28 the standard deviation were \pm 8.567 the results indicate that most of the subjects had moderately psychosocial problem.

\begin{tabular}{cccc}
\hline Sl no & Variables & Mean & SD \\
\hline 1 & Psychosocial problems & 25.58 & \pm 8.567 \\
\hline
\end{tabular}




\subsubsection{Percentage and Frequency Distribution of Level of Quality of Life of Parents with Asthmatic Children $\mathrm{n}=50$}

The table shows the level of quality of life of parents with asthmatic children. Out among 50 subjects $76 \%$ (38) had good quality of life, $16 \%$ (8) has better quality of life and $8 \%(4)$ has poor quality of life

\begin{tabular}{cccc}
\hline Sl no & Category & Frequency & Percentage (\%) \\
\hline 1 & Better & 8 & 16 \\
2 & Good & 38 & 76 \\
3 & Poor & 4 & 8
\end{tabular}

\subsubsection{Mean, Mean Percentage and Standard Deviation to Assess the} Level of Psychosocial Problem with Asthmatic Children $n=50$

The table shows the maximum score of quality of life was 41 with the mean psychosocial problem 28.34 the standard deviation were \pm 8.588 the results indicate that most of the subjects had good quality of life.

\begin{tabular}{cccc}
\hline Sl no & Variables & Mean & SD \\
\hline 1 & Quality of life & 28.34 & \pm 8.588 \\
\hline
\end{tabular}

\subsubsection{Correlation between Level of Psychosocial Problem and Quality of} Life of Parents with Asthmatic Children $\mathbf{n}=\mathbf{5 0}$

The table shows that there is a weak positive correlation between psychosocial problem and quality of life of parents with asthmatic children using karlpearson's correlation analysis is 0.314 .

\begin{tabular}{ccccc}
\hline Sl no & Items & Mean & Standard Deviation & Correlation \\
\hline 1 & Psychosocial problem & 25.88 & 8.56 & 0.314 \\
2 & Quality of life & 28.34 & 8.599 & \\
\hline
\end{tabular}

\subsubsection{Association between Level of Psychosocial Problems and Sociodemographic Data of Parents with Asthmatic Children $\mathbf{n}=\mathbf{5 0}$}

This showed that the association between the levels of psychosocial problem and selected socio demographic variables. The calculated $\times 2$ values was less than table value in selected socio demographic variables such as age, gender, education, occupation, place of residence, income, occupation, number of children, gender of child, age of child, duration of illness and number of hospitalization in a year. The calculated $\times 2$ value was more than table value in selected socio demographic variable such as religion. Hence null hypothesis was accepted and stated as there is no significant association between level of psychosocial problem and socio demographic variable, except socio demographic variable like age.

\subsubsection{Association between Level of Quality of Life and Socio Demographic Data of Parents with Asthmatic Children $\mathbf{n}=\mathbf{5 0}$}

The table shows that the association between levels the quality of life and se- 
lected socio demographic variables. the calculated $\times 2$ values was less than table value in selected socio demographic variables such as age, gender, education, occupation, place of residence, income, occupation, number of children, gender of child, age of child, duration of illness and number of hospitalization in a year. The calculated $\times 2$ values were more than table value in selected socio demographic variable such as religion. Hence null hypothesis was accepted and stated as there is no significant association between level of psychosocial problem and socio demographic variable, except socio demographic variable like family, income, gender of the child.

\section{Discussion}

The findings obtained from the study are discussed under the following objectives.

Objective 1: To assess the level of psychosocial problems and level of quality of life of parents with asthmatic children.

The result shows the level of psychosocial problem on parents with asthmatic children. Out of 50 subjects, 32\% (16) had mild psychosocial problem, 66\% (33) had moderate level of psychosocial problem and 2\% (1) had severe psychosocial problem. The results indicate that most of the subjects had moderately psychosocial problem. Out of 50 subjects $76 \%$ (38) had good quality of life, $16 \%$ (8) has better quality of life and $8 \%(40)$ has poor quality of life.

A study on mothers of children with asthma consisting of 160 mothers of 4 15 years of old children with asthma and the control group consisted of 90 mothers of healthy children. Results indicated that levels of depression and anxiety symptoms were higher in mothers of children with asthma compared to those in the control group $(p<0.001)$ [7].

Objective 2: To find the correlation between scores of psychosocial problem and quality of life among parents with asthmatic children.

The results showed that there is no statistically significant correlation between psychosocial problem and quality of life. Hence the null hypothesis there is no significant correlation between psychosocial problem and quality of life is retained, but a weak positive correlation between psychosocial problem and quality of life of parents with asthmatic children using karlpearson's correlation analysis $(p=0.314)$.

A supportive study was conducted to find the correlation between correlations of depression and sleep quality in mothers of children with and asthma on 148 subjects during 2008-2010. Data were collected using a questionnaire for demographic characteristics, sleep quality and depression scale (HADS). Result of the study showed high levels of depression and poor sleep quality requiring clinical intervention were seen in $37.2 \%, 29.1 \%$ and $39 \%$ of mothers, respectively. A significant correlation was detected between sleep quality and depression ( $p$-value $<0.005)$. A total of $20 \%$ of mothers suffering from depression and a history of cigarette smoking ( $p$-value $<0.005)$. The study concluded that significant correlation between sleep quality and depression in mothers of children suffering 
from asthma [8].

Objective 3: To find the association between level of psychosocial problem and selected socio demographic variables.

The result shows that there is no statistically significant association found between the selected socio demographic variables and psychosocial problem. Hence the null hypothesis stated that there is no significant association between psychosocial problem and socio demographic variable was retained.

A supportive study was done in Italy at department of public health and community medicine, concluded that mothers who had experienced stress were associated with the duration of asthma in children.

Objective 4: To find the association between level of quality of life and selected socio-demographic variable.

The result shows that there is no statistically significant association found between the selected socio demographic variables and quality of life. Hence the null hypothesis stated that there is no significant association between psychosocial problem and socio demographic variable.

The study examines the effect of asthma severity of children aged $7-17$ years and socio-demographic characteristics on the caregivers quality of life. For parents of asthmatic children, there was an association between overall asthma severity and quality-of-life score. Measuring parental quality of life development of effective asthma programs [9].

\section{Summary}

This study deals with the conclusion, health education and recommendations drawn for the study. "A study to assess the psychosocial problems and quality of life of parents with asthmatic children in opd's of Ramaiah hospitals, Bengaluru".

The present study assessed the psychosocial problem and quality of life. Study concludes that among 50 parents, $25 \%$ are having moderate psychosocial problem, $25 \%$ are having mild and mean of 28.82 and standard deviation \pm 0.50508 .

With regards to association between level of psychosocial problem and selected socio demographic variables, there is no association between both the variables, except religion.

\section{Health Education}

${ }^{*}$ More knowledge should be provided to students regarding managing strategies in patients with asthmatic children

*Students should be made aware about the career opportunities in the field of parental management and family management

${ }^{\star}$ Educators should emphasize more on preparing students to impart information to the family supportive care

${ }^{\star}$ Facilities should be made available for students to have direct experience in paediatric pulmonology and supportive family care 
*The students can be encouraged to take up projects and research studies on paediatric asthma and their caregivers

\section{Recommendations}

${ }^{\star}$ The study can be replicated in different settings with larger samples

*An experimental study can be conducted by assessing the effectiveness of teaching programmes on prevention of infection in neonates working in pediatric units

*Survey can be conducted to assess the knowledge of health professionals on prevention of infection of infection among neonates

${ }^{*}$ Develop and promote effective program to improve the knowledge of health professionals on prevention of infection among neonates

${ }^{*}$ Improve curriculum and introduce nursing school based training programmes on supportive care in pediatric pulmonology.

\section{References}

[1] Wong, D.L. (2009) Nursing Care of Infants and Children. 8th Edition, Elsevier Publications, Amsterdam, 345-347.

[2] Agrawal, S., Pearce, N. and Ebrahim, S. (2013) Prevalence and Risk Factors for Self-Reported Asthma in an Adult Indian Population: A Cross-Sectional Survey. International Journal of Tuberculosis and Lung Disease, 17, 275-282. http://www.ncbi.nlm.nih.gov/pubmed/23317966

[3] Animesh, J.I., Vinod, H.B. and Acharya, D. (2010) Prevelance of Bronchial Asthma in Rural Indian Children. A Cross Sectional Study from South India. Indian Journal of Pediatrics, 77, 31-35.

[4] Cerdan, N.S., Alpert, P.T., Moonie, S., Crykiel, D. and Roe, S. Asthma Severity in Children and Quality of Life of Their Parents.

[5] Garro, A. (2011) Coping Patterns in Latino Families of Children with Asthma. Journal of Pediatric Health Care, 25, 347-354.

http://www.ncbi.nlm.nih.gov/pubmed/22018425 https://doi.org/10.1016/j.pedhc.2010.04.005

[6] Ozkaya, E., Cetin, M., Uguard, Z. and Samanci, N. (2010) Evaluation of Family Functioning and Anxiety-Depression Parameters in Mothers of Children with Asthma. Allergol Immunopathol (Madr), 38, 25-30. http://www.ncbi.nlm.nih.gov/pubmed/19836874

[7] Carson, D.K. and Schauer, R.W. (1992) Mothers of Children with Asthma: Perceptions of Parenting Stress and the Mother-Child Relationship. Psychological Reports, 71, 1139-1148. http://www.ncbi.nlm.nih.gov/pubmed/1480693

[8] Behl, R.K., Kashyap, S. and Sarkar M. (2010) Prevelance of Bronchialk Asthma in School Children of 6-13 Years of Age in Shimla City. Indian Journal of Chest Diseases and Allied Sciences, 52, 145-148. http:///www.ncbi.nlm.nih.gov/pubmed/20949732

[9] Moonie, S., Cyrkiel, D. and Oshiro, R.S. (2012) Asthma Severity in Children and Quality of Life of Their Parents. Applied Nursing Research, 25, 131-137. http:///www.ncbi.nim.nih.gov/pubmed/21439791 